\title{
State-of-the-art of fiber-reinforced polymers in additive manufacturing technologies
}

\author{
Hofstätter, Thomas; Pedersen, David Bue; Tosello, Guido; Hansen, Hans Nørgaard
}

Published in:

Journal of Reinforced Plastics \& Composites

Link to article, DOI:

$10.1177 / 0731684417695648$

Publication date:

2017

Document Version

Peer reviewed version

Link back to DTU Orbit

Citation $(A P A)$ :

Hofstätter, T., Pedersen, D. B., Tosello, G., \& Hansen, H. N. (2017). State-of-the-art of fiber-reinforced polymers in additive manufacturing technologies. Journal of Reinforced Plastics \& Composites, 36(15), 1061-1073. https://doi.org/10.1177/0731684417695648

\section{General rights}

Copyright and moral rights for the publications made accessible in the public portal are retained by the authors and/or other copyright owners and it is a condition of accessing publications that users recognise and abide by the legal requirements associated with these rights.

- Users may download and print one copy of any publication from the public portal for the purpose of private study or research.

- You may not further distribute the material or use it for any profit-making activity or commercial gain

- You may freely distribute the URL identifying the publication in the public portal 


\section{State of the Art of Fiber-Reinforced Polymers in Additive Manufacturing Technologies}

Thomas Hofstätter *1, David B. Pedersen ${ }^{1}$, Guido Tosello ${ }^{1}$, and Hans N. Hansen ${ }^{1}$

${ }^{1}$ DTU Mechanical Engineering, Technical University of Denmark

* Corresponding author: thohofs@mek.dtu.dk

Additive manufacturing technologies have received a lot of attention in recent years for their use in multiple materials such as metals, ceramics, and polymers. The aim of this review article is to analyze the technology of fiber-reinforced polymers and its implementation with additive manufacturing. This article reviews recent developments, ideas, and state-of-the-art technologies in this field. Moreover, it gives an overview of the materials currently available for fiber-reinforced material technology.

Keywords: Additive Manufacturing Technology, Fiber-Reinforced Polymers, Review

\section{Introduction}

This article emphasizes the current state of the art in fiber-reinforced polymers (FRPs) in additive manufacturing (AM). It gives an overview of the currently available technologies and materials, including their properties and influence on composite structures. As literature reviews on FRP in AM are rare, this article elaborates on potential manufacturing technologies and configurations pointing out current applications and giving an insight into the current state of the art. FRPs and applications in multiple industries such as aerospace, automotive, wind energy, production industry, and biomedical engineering. FRPs are based on highly strain-resistant fibers embedded into a softer polymer matrix. This can, on the one hand, take place in an ordered manner using directional fiber placement within the matrix, and on the other hand, in a non-ordered manner. The aim of the fibers is to strengthen the material in terms of load, whereas the aim of the polymer matrix is to protect the fibers and to distribute the load among them [1]-[4]. The directional fiber placement will result in anisotropic mechanical properties whether placed in an ordered or unordered manner, whereas the stress and strain resistance will increase only in the direction of the fibers. Moreover, Fibers and matrix material need to interact

at their interface to distribute stress.

The materials need to be chemically compatible. Microcracks close to the interface between fibers and matrix lead to a significant loss of stiffness and strength [7]-[9]. Other advantages of fiber-

reinforcement were summarized in [10] as:

better out-of-plane properties for multi-directional preforms and for printing spatially oriented fibers;

- broad structural designability;

- improved structural integrity and damage tolerance; and

- cost-effectiveness. 
It was pointed out in [11] - [13] that fiber-reinforcement comes with advantages in terms of the distortion of the object during the printing process. This allows larger objects to be printed. In [11], the authors were able to manufacture lighter beams with the same strength parameters using fused deposition modeling.

\section{Fiber Material}

Two groups of sources for fibers can be identified: natural fibers and synthetically fabricated fibers. The first group, natural fibers, can be further separated into fibers from plants and fibers from animals. Cellulose fibers from plants are a widely used example [14], [15]. Synthetic fibers are fabricated under dry or wet conditions. After production, they are spun into filaments, ropes, or strings [2]. Commonly used fibers for carbon fiber-reinforced polymers (CFRP) are carbon fibers [16]. They are widely used in the Airbus A350 aircraft, components in the automotive industry, wind turbine blades, and endoscopic surgery [5], [17], [18]. Carbon nanotube (CNT) composites in a polymer matrix are reviewed in [4]. However, the article does not elaborate on additive manufacturing using CNTs. CNTs reach a tensile strength of 100 to $600 \mathrm{GPa}$ and Young's moduli of 1 to $5 \mathrm{TPa}$. These properties make it necessary to invest in a good interface between the CNTs and the surrounding matrix. Research has also been performed on the usage of glass fibers in combination with additive manufacturing processes ([7], [19]-[23]). This will be described in section 4.1. Long glass fibers allow the transportation of information through the material and therefore also allow communication through the matrix material [24]. Aramid fibers were used in [25] described in section 4.5.

Vapor-grown carbon fibers (VGCF) were used in [26] mixed by shear processing and focused on an alignment of the fibers and avoidance of fiber breakage. VGCFs come with high stiffness and strength as well as low weight.

Other advantages are the electrical and thermal properties of $50 \mu \mathrm{cm}$ and $2000 \mathrm{~W} / \mathrm{mK}$. Experiments performed by [96] on a carbon fiber filled fused deposition modeling printer (as will be described in the specific section) concluded a resistivity of $0.09 \pm 0.01 \mathrm{ohm} / \mathrm{m}$ within the printed layer and $0.12 \pm 0.01$ $\mathrm{ohm} / \mathrm{m}$ orthogonal to the printed layers. The measurements were taken out on a $5 \mathrm{~mm}$ cube of a commercial formulation of polycaprolactone $(P C L)$ matrix.

Young*s module is located at high values of 360 to $600 \mathrm{GPa}$ [27]-[30]. A range of natural fibers was described in [31].

A characterization of silicon carbide (SiC) fibers for applications influenced by high temperatures is given in [32].

\section{Matrix Material}

There is a wide range of polymer matrix materials available in conventional manufacturing processes, including polypropylene (PP), polystyrene (PS), and polyurethane (PU). Currently, three technologies are available in literature to produce raw composite material. They are solution casting, in situ polymerization, and melt compounding [33], [34]. Also commonly used as matrix material are epoxy, polyester, and acrylate blends featuring a high surface quality in terms of roughness and a good connection to glass fiber material [7].

In terms of AMT, the range of employed polymers is currently limited. It includes but is not exclusive to examples of the application of acrylonitrile butadiene styrene (ABS), polycarbonate (PC), polylactide (PLA), polyamide (PA), tetraethyl orthosilicate (TEOS), and polyphenylsulfone (PPSF) [5], [26], [35], [36].

High performance polymers are not very common in Additive Manufacturing Technologies (AMT). In [37] polyetherimide (PEI) of the polyetherethercetone (PEEK) family was used as a matrix material. $A$ 
main advantage is the high glass transition temperature of over $200 \mathrm{C}$. A model with polymethyl methacrylate (PMMA) powder which was later melted around the fibers was implemented in [38]. In [2], Polypropylene (PP) was discussed as matrix material in detail, naming the main advantages of $\mathrm{PP}$ as a high heat-distortion temperature, flame resistance, dimensional stability, and suitability for filling, reinforcing, and blending.

PLA was used as a matrix material for microcrystalline cellulose (MCC) whiskers in [33], [39], [40]. After a swelling process involving N,N-dimethylacetamide (DMAc) containing lithium chloride (LiCl), the whiskers were mixed with PLA-melt during the extrusion process forming an all biodegradable composite material with increased strength by $20 \%$ and Young's modulus by $10 \%$ at a fiber content of $5 \%$ in weight. Although PLA is widely used in additive manufacturing, especially in Fused Layer Manufacturing (FLM), few applications of this composite in actual components are available in literature.

FLM is also known under the commercial trademark Fused Deposition Modeling (FDM) which is commonly known and therefore used throughout this paper.

Concerning ultraviolet-assisted 3D (UV-3D) printing, an investigation was performed in [41] of short carbon fibers with a co-formulation of a photocurable acrylic resin with a thermocurable epoxy resin with the raw materials Bisphenol A diglycidyl ether (DGEBA), 1,1-dimethyl, 3-(3',4'-dichlorophenyl) urea (Diuron ${ }^{\mathrm{TM}}$ ), dicyandiamide (DICY), and fumed silica.

\section{Technologies for the Implementation of FRP}

A tabular overview on the FRPs already produced by AMT is given in Tab. 1. All fiber percentage values are stated in weight content.

\subsection{FRP in FDM Manufacturing}

FDM manufacturing using CF in ABS is possible and can result in increased tensile strength of $42 \mathrm{MPa}$ at $5 \%$ fiber content in weight as shown in [5]. At a fiber content of $10 \%$ in weight, the tensile strength was $34 \mathrm{MPa}$, which is close to the tensile strength of pure ABS (depending on the composition of the $A B S$ ). Young's modulus was largest at 7:5\% fiber content in weight with a value of 2.5GPa. Toughness and yield strength decreased when adding fibers to pure ABS.

The same accounts for ductility. Experiments were performed with fiber lengths of $150 \mu \mathrm{m}$ resulting in a higher Young's modulus than with $100 \mu \mathrm{m}$. It was concluded in [5] that a pure plastic specimen compared to added carbon fiber into plastic materials could lead to an increased tensile strength and Young's modulus, but also to a decreased toughness, yield strength, and ductility.

An orientation of $91.5 \%$ of the embedded carbon fibers were concluded to reach the optimal mechanical properties in [42], using fibers with the length of 200 to $400 \mu \mathrm{m}$. Experiments concluded an increase of tensile strength by approximately $115 \%$ and Young's modulus by approximately $700 \%$. This value is the highest among the reviewed literature.

A similar experiment was performed earlier in [26] using VGCF in an ABS matrix. After Banbury mixing, extrusion, and FDM manufacturing, limited porosity of the composite and an average tensile strength increasing of $15 \%$ up to a value of $24.4 \mathrm{MPa}$ (increase of $29 \%$ ) at the highest level was observed. The absolute values strongly depended on the composition of the ABS polymer.

FDM of ABS with short glass fibers that were showing the ability of up to a $30 \%$ glass fiber content in weight in an ABS matrix were performed in [19], [20]. Higher values require chemical treatment of the ABS in terms of plasticizers and compatibilizers to provide a uniform distribution of the fibers. This allows uniform and determined material parameters throughout the final part.

FDM was used in combination with FRPs and achieved an increase of the modulus by $40 \%$ with a weight content of chopped carbon AS4 fibers of $10 \%$ in [37]. Moreover, the moisture content was reduced by this fabrication step, which reduced the porosity of the printed objects. 
Other experiments using FDM in combination with FRPs are presented in [11], [12], [43], including natural wood fibers in [14] investigating the fiber orientation after the FDM print. It was pointed out that FDM prints include a high porosity of around $20 \%$ leading to damage mechanisms and water absorption, including swelling. An increasing porosity with increasing nozzle width was detected. Similar results about the microstructural characteristic of FDM-produced parts were presented in [44] investigating carbon fibers in an ABS matrix. For the sake of uniform reinforcement, the prints were not performed in a layered manner, but with multi-axe, 3D-extrusion technology.

Whereas the above-mentioned research concerns short fibers, an investigation in [15], [92] concerning continuous, fiber-reinforced, FDM technologies using PLA with short carbon fibers or continuous twisted yarns of natural jute fibers is available. It was shown that unidirectional carbon fiber-reinforced plastic are equipped with mechanical properties superior to jute-reinforced and unreinforced thermoplastics. An improvement of continuous fiber-reinforcement above conventional 3D-printed polymer-based composites in terms of tensile strength was present. The jute fibers did not significantly increase the tensile strength, whereas the carbon fibers increased the tensile strength by 435 to 599 $\%$. Investigations using PLA with an embedded continuous fiber was presented in [45] concluding a weak interface between the fiber and the matrix and flexural strengths increased from 13.8 to $164 \%$ and storage moduli from $166 \%$ to $351 \%$ increased compared to conventional parts. A general overview on the use of continuous fiber in a PLA matrix is given by [95].

Short jute fibers were investigated in [46]. Compared to [15], the strengthening of the ABS matrix material was lower and located at $9 \%$ for tensile strength in unidirectional tensile testing with 5\% fiber content in weight. It was also concluded that the fibers located themselves in the middle of the printed layer.

A similar system using ABS as matrix material for big-area additive manufacturing (BAAM) was established in [47] using short carbon fibers at $20 \%$ in weight resulting in $100 \%$ increase in strength and $380 \%$ in stiffness and, at $40 \%$ in weight, resulting in 380\% increase in strength and $470 \%$ increase in stiffness. Computational fluid dynamics (CFD) simulations modeling the fiber distribution within an FDM nozzle and final product were performed in [48]. Investigations using Computed Tomography (CT) were presented in [87] for objects manufactured by FDM using PLA and short carbon fibers as matrix and fiber material. A conclusion was drawn in terms of fiber orientation during the final part in strong relation to the printing orientation in the FDM process. Due to the two cycles of extrusion of the material (1) when generating the filament from granule; and (2) during the AM process, fibers were oriented longitudinally to the printing path.

Elipsoidic holes with the major axis in the nozzle orientation occurred in the PLA matrix with average sizes of 50 to $100 \mu \mathrm{m}$ possibly resulting in a reduction of tensile strength. Compared to FRP in digital light processing (DLP), the size of the holes was significantly increased [49]. A similar discovery was made by [94] showing droplets spreading along the fibers. The interface between fiber and matrix material has significant influences on the tensile strength. The distribution of fibers was therefore also influenced whereas the fibers were generally oriented in the middle of the extrusion line [49], [91]. The interface between the layers was indistinct due to the remelting of material during the extrusion of the next layer, allowing for a continuous matrix material. This also resulted in an interconnected orientation of longitudinally-oriented and orthogonally-oriented fibers.

The interface between the fibers and the PLA matrix was destroyed during a tensile-test. This was fatal at the layers with orthogonal fiber orientation towards the tensile strength. $40 \%$ of all fibers in a longitudinal orientation towards the tensile strength were ripped out of the matrix at the fracture surface. A device to align fibers in the FDM nozzle was recently patented [50] in 2016, claiming reinforcement of the polymer due to the directional fiber distribution. A modified nozzle design using multiple matrix materials was described in [51]. The nozzle provided the ability to include fibers and increase mechanical properties. The design is claimed to reduce the staircase effect, warp, and gaps as well as selective reinforcement and load-based infill. 
Despite the short carbon fibers described above, continuous fused manufacturing was developed by the company MarkForged [90] offering ABS matrix material with Nylon-micro-carbon, carbon, nylon, fiberglass, Kevlar and high-temperature fiberglass as fiber materials.

\subsection{FRP in Stereolithography (SLA)}

The possibilities of manufacturing three-dimensional, printed objects with additives using mask stereolithography (mSLA), also known as direct light processing (DLP), were investigated in [21].

Glass fibers were chosen for the process with a diameter of 10 to $15 \mu \mathrm{m}$. A weight content of $10 \%$ was selected to reach optimal mechanical parameters, but still keep viscosity of the resin in an applicable regime. The experiments described in [21] were unsuccessful even with a weight content of 3 to $5 \%$. It was not possible to mix the resin with the fibers and keep the concentration in an isotropic distribution. From the experiments, it was concluded that the concentration of the fibers needed to meet specific levels to gain proper results.

Experiments using carbon nanotubes were performed, investigating a UV-curable resin in a mixture with carbon nanotubes of 0:1 to $5 \%$ weight ratio [52]. The experiments were performed using molds filled with the curable resin which were then cured under UV light for 30 to $120 \mathrm{~min}$. Other results of FRPs in UV-curable resins was presented in [53].

Earlier research was undertaken in [54] using Somos 7110 epoxy-based resin and layered, looselywoven, long, fiber material. It demonstrated the possibility of increasing the elastic modulus along the direction of the fibers due to the fact that they created a layered fiber structure.

Short glass fibers have also been used [55]. The fibers were mixed into the resin and were therefore randomly oriented in space, resulting in a uniform reinforcement. Adding 15\%, they calculated an increase of the tensile modulus from 1.5GPa to 2.5GPa [22], [55] calculated the modulus by the equation 


$$
E_{c}=\chi_{1} \chi_{2} \Phi_{f} E_{f}+\Phi_{m} E_{m}
$$

where

$E_{c}=$ tensile modulus of the composite

$E_{f}=$ tensile modulus of the fiber

$E_{m}=$ tensile modulus of the matrix

$\Phi_{f}=$ volume fraction of the fiber

$\Phi_{m}=$ volume fraction of the matrix

$\chi_{1}=$ orientation-efficiency factor

$\chi_{2}=$ fiber-length correction factor

and

$$
\begin{aligned}
\chi_{2} & =\frac{l-\tanh (n a)}{n a} \\
n & =\sqrt{\frac{2 E_{m}}{E_{f} \ln \left(\frac{2 R}{d}\right)}} \\
G_{m} & =\frac{E_{m}}{2(1+\nu)} \\
\frac{2 R}{d} & =\sqrt{\frac{\pi}{4 \Phi_{f}}} \\
a & =\frac{l}{d}
\end{aligned}
$$

where

$$
\begin{aligned}
& l=\text { length of the fiber } \\
& d=\text { diameter of the fiber } \\
& a=\text { dimensionless length } \\
& n=\text { dimensionless length } \\
& R=\text { dimensionless length } \\
& \nu=\text { Poisson number }
\end{aligned}
$$

The factor $\mathrm{X}_{1}$ depends on the fiber orientation ( 0.2 for three-dimensionally randomly oriented and 1 for unidirectional orientation). Experiments using molding technology showed an increase of tensile strength by $64 \%$. Experiments using rapid prototyping stereolithography showed an increase of tensile strength by $60 \%$ whereas the level of the tensile strength is located at half the value of the material used for the experiments manufactured by molding [22], [55]. 
The manufacturing machine used in [55] implemented a combination of fused deposition modeling and stereolithography feeding the material from a mixing device directly onto the surface where it was cured using ultraviolet light.

A different study, also using short glass fibers in an urethane acrylic-based resin cured with a laser system, was performed in [22], [23]. It showed an increase of the mechanical parameters in dependence on the angle of the fiber. Moreover, the shrinkage of usually 1 to $6 \%$ was reduced by the short glass fibers. The mechanical properties were directly connected to the fiber concentration, increasing the strength when increasing the fiber content. Moreover, the laser power and lower layer pitches were found to increase the mechanical strength. Shrinkage decreased with increasing fiber content.

Building on this research, other filler material of which carbon can be considered the most similar one to fiber-reinforced polymers was added in [56]. The authors were able to significantly increase the mechanical properties by adding so-called "carbon black" with particle sizes of $30 \mathrm{~nm}$.

In terms of coventional manufacturing, a review of the flow characteristics of a resin filled with fibers is given in [57]. A special focus was set on the characteristic flow on the corners of objects when coating parts with the resin. It was claimed that residual stresses inducing defects such as cracking and delamination are inevitable. Research according to [57] should go into the direction of microbuckling of fibers, void formation, as well as global layer buckling and resin percolation at corners.

As the SLA process is based on a layer-wise build-up of the manufactured object, fiber orientation within the object is limited by the fiber characteristics and the layer height. Orientation and distribution of fibers were investigated for the first time in [49]. It was demonstrated that a fiber-filled structure could be printed using digital light processing (DLP) technology showing an even fiber distribution in the direction of the manufacturing layers. This allows reinforcement in the orientation of the layers by placing the part according to the desired reinforcement direction. Other directions were only minimally bound by the carbon fibers for physical reasons as the layer thickness of $35 \mu \mathrm{m}$ was significantly smaller than the average fiber length of $100 \mu \mathrm{m}$. No clustering around edges was detected, allowing the conclusion of a more even distribution of fibers standing in contrast to injection moulding. Postprocessing was necessary due to the fact that the carbon fibers were not affected by the visual curing in the DLP machine. Therefore, the fibers were standing out of the boundary of the object. This resulted in an uneven surface, which needs to be further processed. It was furthermore inspected that a clustering of $30 \%$ of all fiber placements happened among the fibers and is shown in a scanning electron microscope (SEM) analysis in Fig. 3.

This resulted in holes in the polymer affecting the strength and durability of the material. Looking at the entire part, the fibers were evenly distributed among the photopolymer, allowing the conclusion that no major sedimentation due to the different material densities occurred during the printing process. Gaps between the fibers and the polymer with the diameter of 1 to $2 \mu \mathrm{m}$ resulted in cracks of the polymer shown in Fig. 4 with an average length of 3 to $4 \mu \mathrm{m}$ which would affect the strength of the final part.

\subsection{FRP in Additive Gypsum Printing Manufacturing}

While most references discussed the implementation of FRP on FDM (or a modification of FDM) and SLA, in [58] fibers were added to a matrix of cellulose-modified gypsum powder. The authors used a ZPrinter 300 by ZCorporation with a layer thickness of $0.1 \mathrm{~mm}$. As fibers, polyacrylonitrile fiber fillers (PAN), polyacrylonitrile shortcut fiber (PAN-Sc), polyamide fiber fillers (PA), and alkali resistant zirconium silicate glass shortcut fiber (glass fiber) were discussed. Fibers at a content of $1 \%$ of weight ratio and the matrix were mixed before the manufacturing process was started. This led to an anisotropic direction of the fibers within the matrix, which stands in contrast to the experiments using FDM. The bending strength was increased by up to $180 \%$ while flexural strength was increased by up 
to $400 \%$. A fiber weight content of over $1.5 \%$ led to a slight decrease. Printing was performed with a fiber content of up to $2.5 \%$ in weight.

\subsection{Fiber Encapsulation Additive Manufacturing (FEAM)}

A new technology, namely fiber encapsulation additive manufacturing (FEAM), was introduced in [59]. It combines the advantages of FDM technology with the reinforcement by long fibers. The fiber is placed onto a surface and covered with a mantle of melted polymer from an FDM extruder.

The technology allows the equipping of the manufactured object with certain properties of mechanical parameters as well as magnetic properties. It is furthermore possible to generate adaptive surface properties [60].

\subsection{Other AMTs}

Randomly-oriented multi-material (ROMM) using a Polyjet 3D Printing (3DP) machine was introduced in [3]. Nevertheless, there have not yet been any known attempts to implement a technology on 3D printing FRPs. An experiment was conducted using 3DP with fiberglass or an aramid fiber and a layer thickness of $0.028 \mathrm{~mm}$ [25]. It could be shown that Young's modulus with fiberglass was significantly increased from $2100 \mathrm{MPa}$ of the non-reinforced material to $3700 \mathrm{MPa}$. While the strength of the nonreinforced object was relatively constant, the strength of the reinforced object varied strongly. An attempt to embed fibers into a laminated object manufacturing (LOM) process using continuous fiber ceramic matrix composites (CMCs), and short fiber CMCs was performed in [61]. The layers finally had a thickness of 230 to $260 \mu \mathrm{m}$ and a relatively high fiber content compared to the FDM process as described above of approximately 50\%. Other examples were given in [62] concluding the increased strength and reduced weight.

Research on highly-ordered fiber composites has been conducted in [36], aiming at the development of military applications in the field of aerospace using biologically-inspired composites with short fibers having a length of around $3 \mathrm{~mm}$. Glass fibers with $\mathrm{ZnO}$ coated by TEOS were used resulting in selfhealing of the composite material in case of defects. The system is inspired by the fiber-based structures of tendons and their interaction among each other. The synthetic fibers were aligned acoustically with ultrasonic waves.

Direct writing was presented in [63] using nylon fibers in a soft, UV-curable, matrix material. The fibers were electrically aligned before the application on the surface.

Ultrasonic consolidation (UC) or ultrasonic additive manufacturing (UAM) is one of the novel methods in additive manufacturing related to laser welding processes. The technology is capable of including fiber composites for localized strengthening using long and short fibers, as well as optical data transmission using long optical fibers as described by [64]. This also includes a potential for actuation. For instance, SiC fibers were embedded into an Al 3003 matrix [65]-[67]. In [24], embedded optical fibers into a metal coating were presented. In [68]-[70], NiTi fibers in an Al matrix were described. It was pointed out that fiber-reinforcement contradicts the shrinkage of the matrix material after the welding process. Carbon fibers were embedded by [88] in an Al matrix.

Implementation of composites in a selective laser sintering (SLS) process generating a metal matrix using graphene oxide (GO) as filling material, enhancing the mechanical properties was presented in [71], [72]. Experiments with carbon fiber were performed in [73]. They were sintering carbon nano fibers (CNF) from PA12 with 3\% content in weight. It was possible to increase the strength of the object as well as the storage module by $22 \%$.

Another approach was performed [38] where carbon and metallic fibers were embedded into a PMMA bed. Tensile strength was thereby increased by $27 \%$. 


\section{Applications of FRP by Additive Manufacturing}

Applications of FRPs in conventional manufacturing are widely known and often used. Applications for AMT are currently rare and mostly focus on FDM. Advantages such as light weight and increased strength for multiple applications were pointed out by [62].

\subsection{Applications in Biomedical Engineering}

Strategies to induce self-healing behavior in FRP-based composites were introduced in [7]. The aim was to induce a self-healing functionality in the polymers by filling the fiber tubes with a healing agent. It was concluded that it was difficult to exactly locate the fibers in the epoxy polymer which increased the production costs considerably. Recent research was conducted with non-ordered filled fibers [8], [74].

So far, there are no approved applications of additive manufacturing of FRP in the field of medicinerelated technologies. A summary of the possibilities of AMT in biomedical engineering focusing on tissue and scaffold generation is given in [75]. It was concluded that the main advantage of AMT is located in the reproduction of hierarchical structures.

In [76], fiber-reinforced polymers in biomedical engineering discussing biologically-inspired materials using direct printing were reviewed. It could be concluded that the storage module and the shear stress increased significantly when the polymer was filled with SiC fibers.

\subsection{Applications in Aerospace}

Research performed by NASA and published in [37] aimed to reduce emissions, fuel burn, and weight of the turbofan engines of business jets. For this aim, FRPs were used in combination with the FDM printing of chopped carbon fiber in a polyetherimide for a valve on the first stage of the compressor blade.

Another example of the commercial use of FRP and AMT in aerospace is the Airbus A350XWB as well as the Airbus A380 [5], [17], [77] where weight reduction at similar or higher strengths are key issues.

The properties of FRP in AM, comparing carbon fiber-reinforced parts produced by AM with aerospace-quality aluminum, mentioning the following advantages in terms of the application were discussed in [11], [93]. It concluded that production rates are extremely low and that the physical size of the parts is generally small. Moreover, the mechanical properties of the polymer parts are generally poor, which limits the potential for direct part replacement and functional use of the polymer components.

\subsection{Applications in Injection Molding}

The aim of this technology is to replace conventional injection molding (IM) cavities by inserts manufactured by DLP at a cost of reduced lifetime and with the advantages of reduced costs, production time, and environmental impact. Investigations in [78], [79] indicated that, for chosen IM insert sizes and geometries, DLP as a production method with plain photopolymer without fibers is environmentally preferable against all compared options for a small numbers of shots, i.e. until about 90 shots.

This rose step-wise potential impact for the polymer above 90 shots, since the assumed lifetime for the metal inserts was much longer than for the PM. The break-even investigation showed that photopolymers are the preferable option for up to 100 to 300 shots, both in terms of climate change impact and human toxicity. Lifetime was significantly increased by adding short carbon fibers into the photopolymer matrix with the influencing parameters of fiber orientation within the IM insert [49], [80]. It was concluded that the lifetime of fiber-reinforced IM inserts could be extended compared to plain IM inserts. The surface wear in terms of mean surface roughness was negligible when inspecting the 
surface without crack-like features. The surface roughness changes were negligible as can be seen in Fig. 6.

Minor cracks on the surface appeared as early as from 300 shots but did not propagate to the major cracks shown in Fig. 6, and therefore did not result in the fatal failure of the entire insert. Propagation of major cracks through the entire insert were found to spread more slowly compared to plain inserts. Thus, it was concluded that the lifetime of the insert was increased by generating a composite using short carbon fibers by $800 \%$.

Additively-manufactured, fiber-reinforced inserts can be considered suitable for pilot production with low part numbers, and are therefore an effective alternative to more expensive inserts made from brass or steel.

\subsection{Applications in Racing}

Combining the need for high individualization, high strength, light weight, and a low production number, Formula 1 (F1) racing cars use fiber-reinforced SLS parts with carbon fibers in their wheel suspension [72].

FDM technology has been used to build an oil sump with increased mechanical properties, combined with the advantage of a more free design of the layered structure of the FDM part in comparison to conventional manufacturing [81], [82].

\subsection{Applications in Train Technologies}

Modern technologies such as the powertrain are critical in structure weight. Big area additive manufacturing for prototyping was used by [89].

\section{Summary and Conclusion}

Several solutions for FRP in additive manufacturing have been recently investigated and are currently available. Experiments using FDM, SLA, UC, LOM, and gypson printing in combination with short fibers were successful. LOM was also performed with long fibers. Current applications for additively manufactured FRPs are rare, although there are multiple conventional applications using short and long fibers embedded in a polymer matrix, such as aerospace, automotive, wind energy, and biomedical engineering. Only in the last field, biomedical engineering, was a potential application pointed out where additive manufacturing might be able to intelligently deposit fibers into the polymer to customize mechanical properties.

FRPs, in any case, lead to new mechanical, thermal, and chemical properties of the polymer matrix. The alignment and proportion of the fibers compared to the matrix have a critical influence on these properties.

It can be concluded that the potential for FRPs in additive manufacturing can be considered as very promising for future applications. However, most technologies for embedding FRPs in additively manufactured products are currently not fully developed. This aspect will need particularly dedicated research efforts in order to increase the applicability of FRPs in AMTs. 


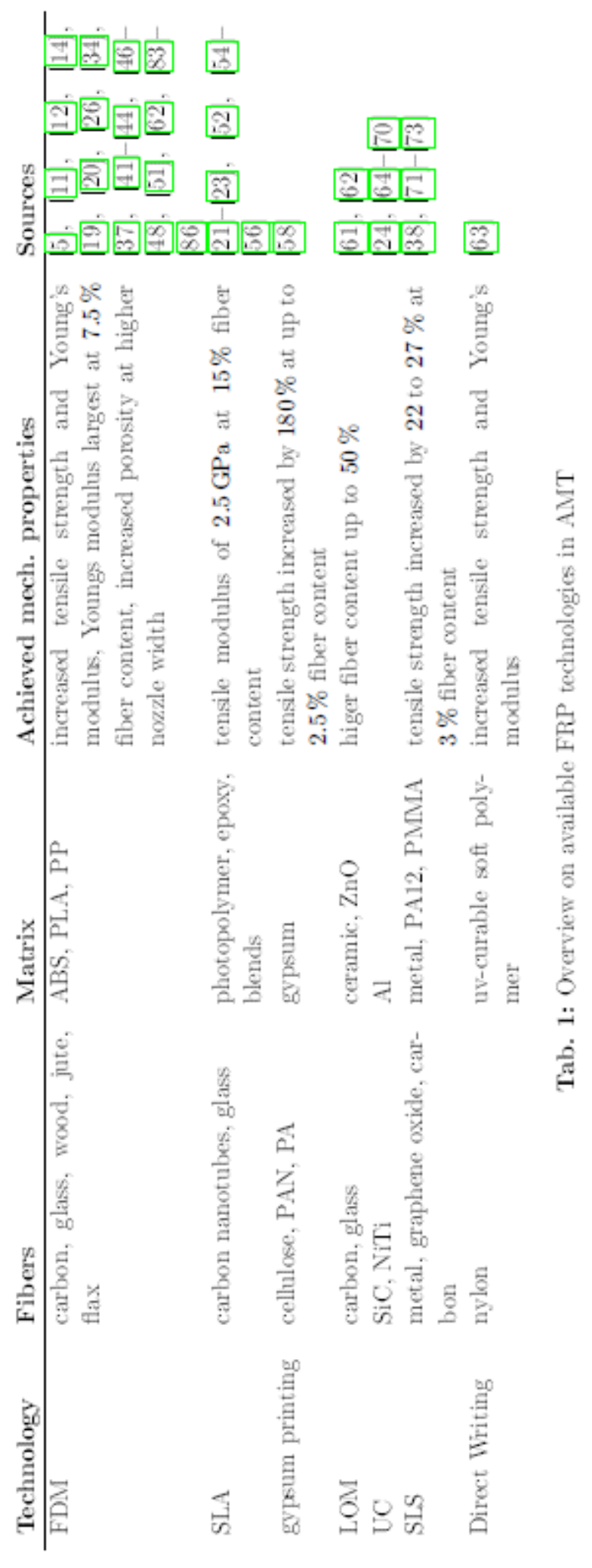




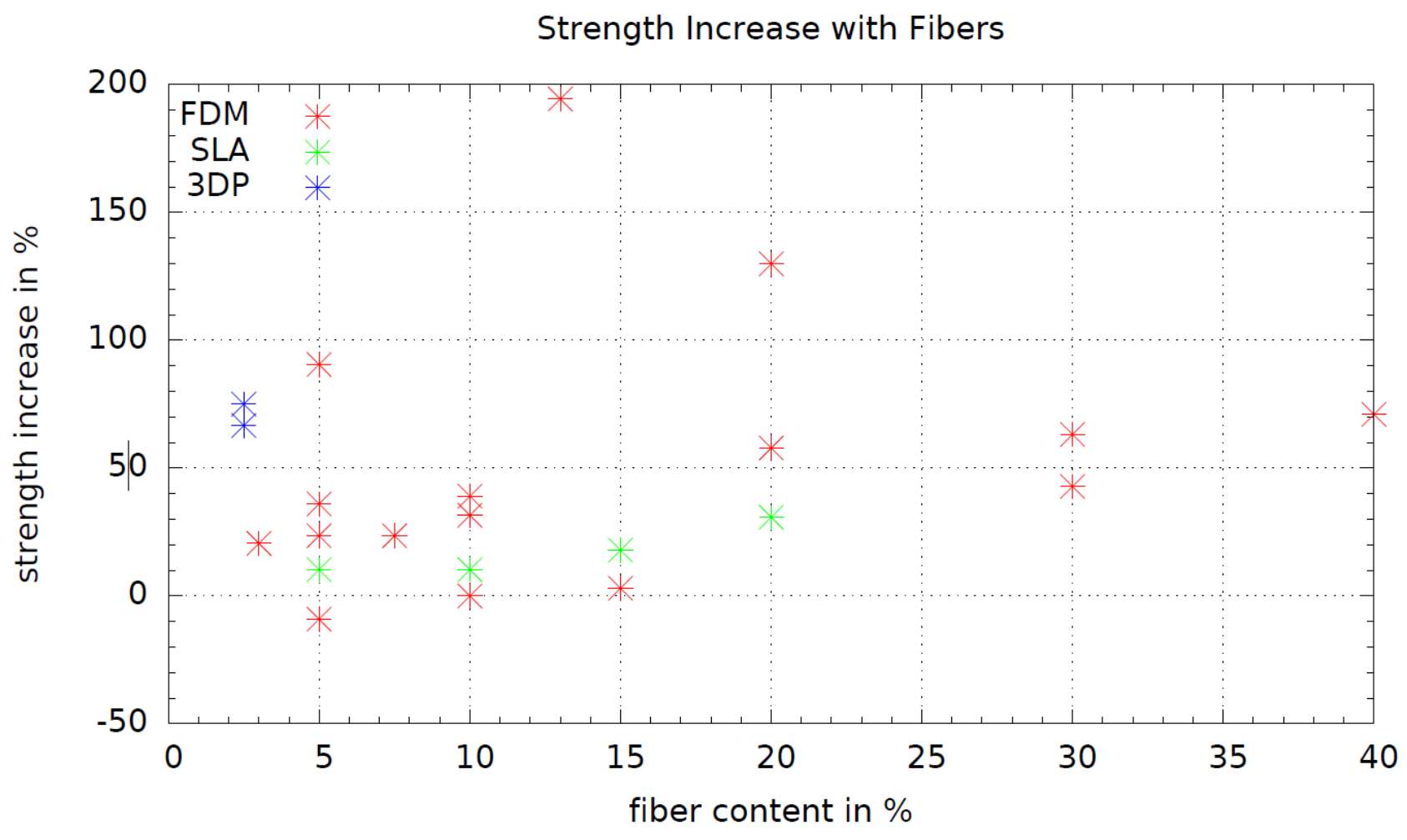

Fig. 1: Strength increase in relation to the fiber content in weight [5], [11], [12], [22], [26], [33], [34], [42], [46], [47], [58] 


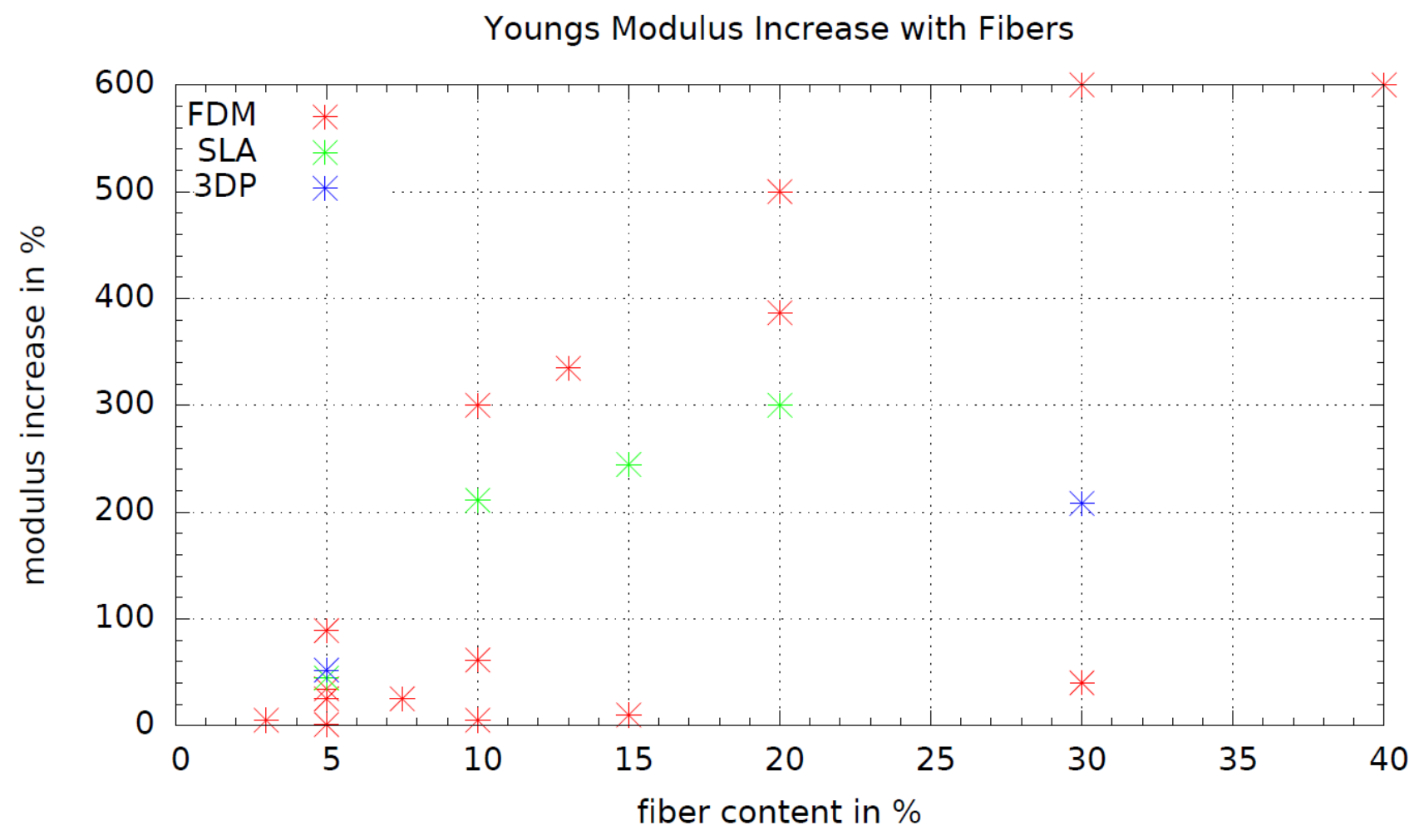

Fig. 2: Young's modulus increase in relation to the fiber content [5], [11], [12], [22], [26], [33], [34], [41], [42], [46], [47] 


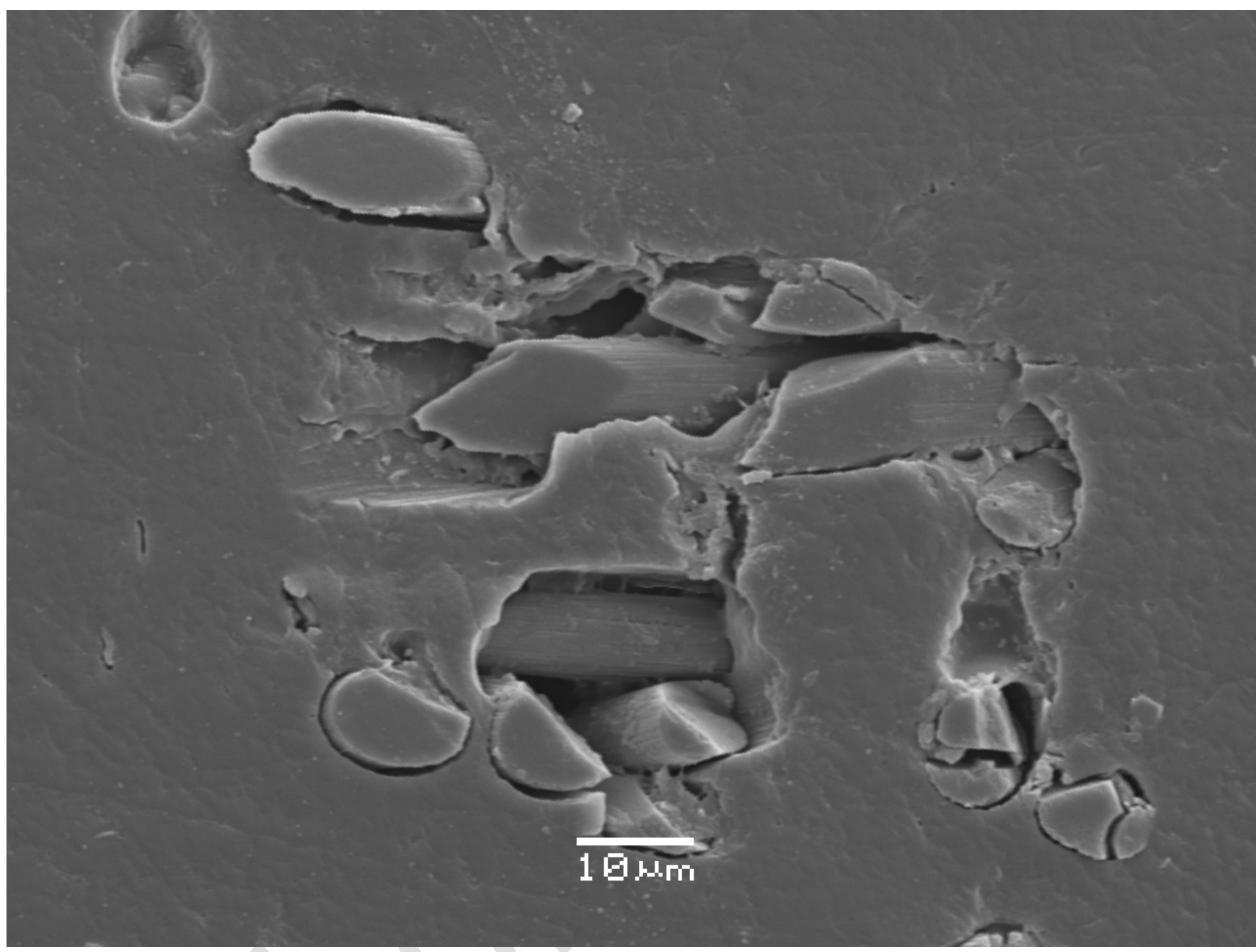

Fig. 3: Clustering of fibers in a DLP processed photopolymer in [49]. Used with permission. 


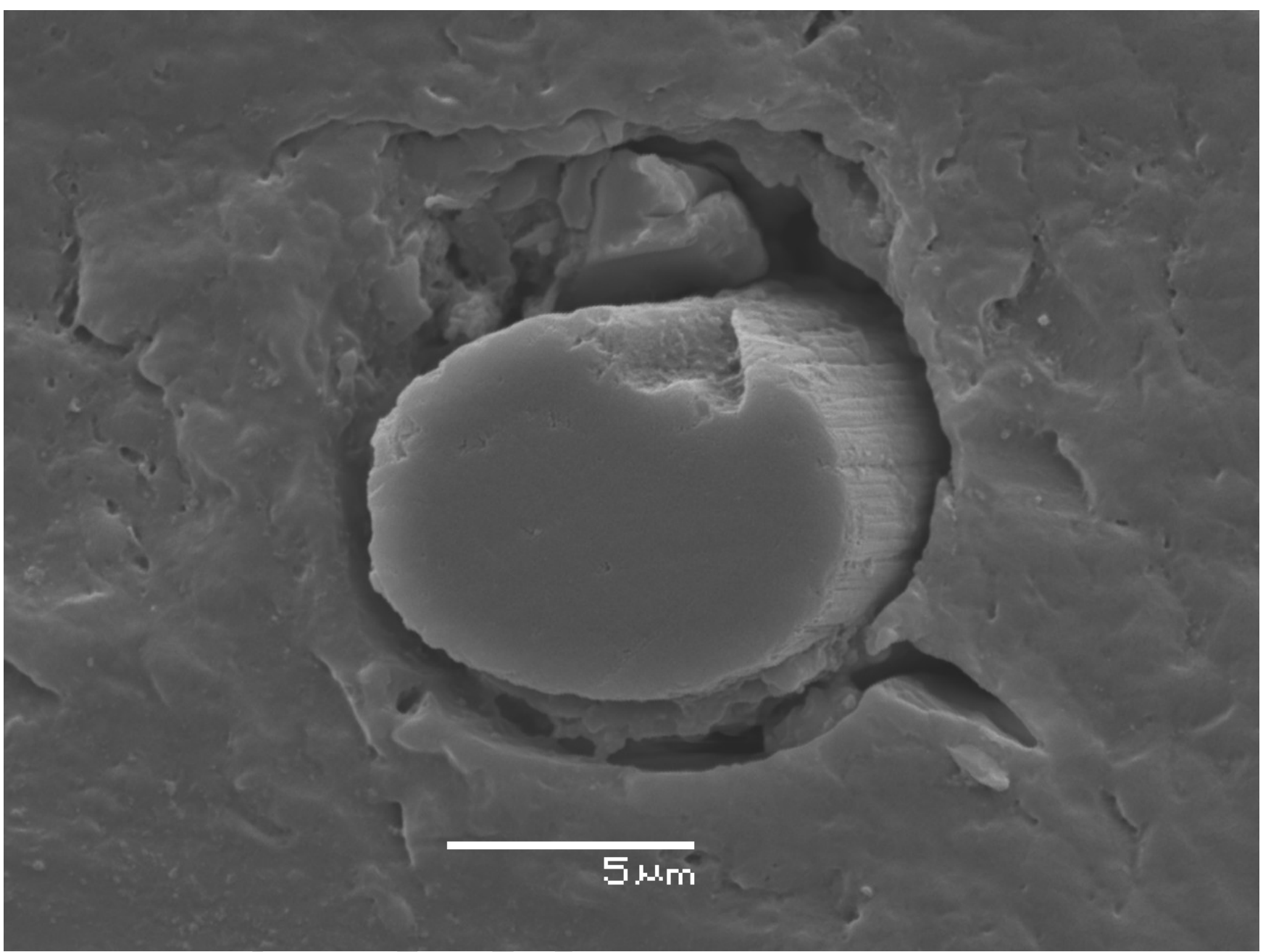

Fig. 4: Gaps and cracks in a DLP processed photopolymer around a carbon fiber in [49]. Used with permission. 


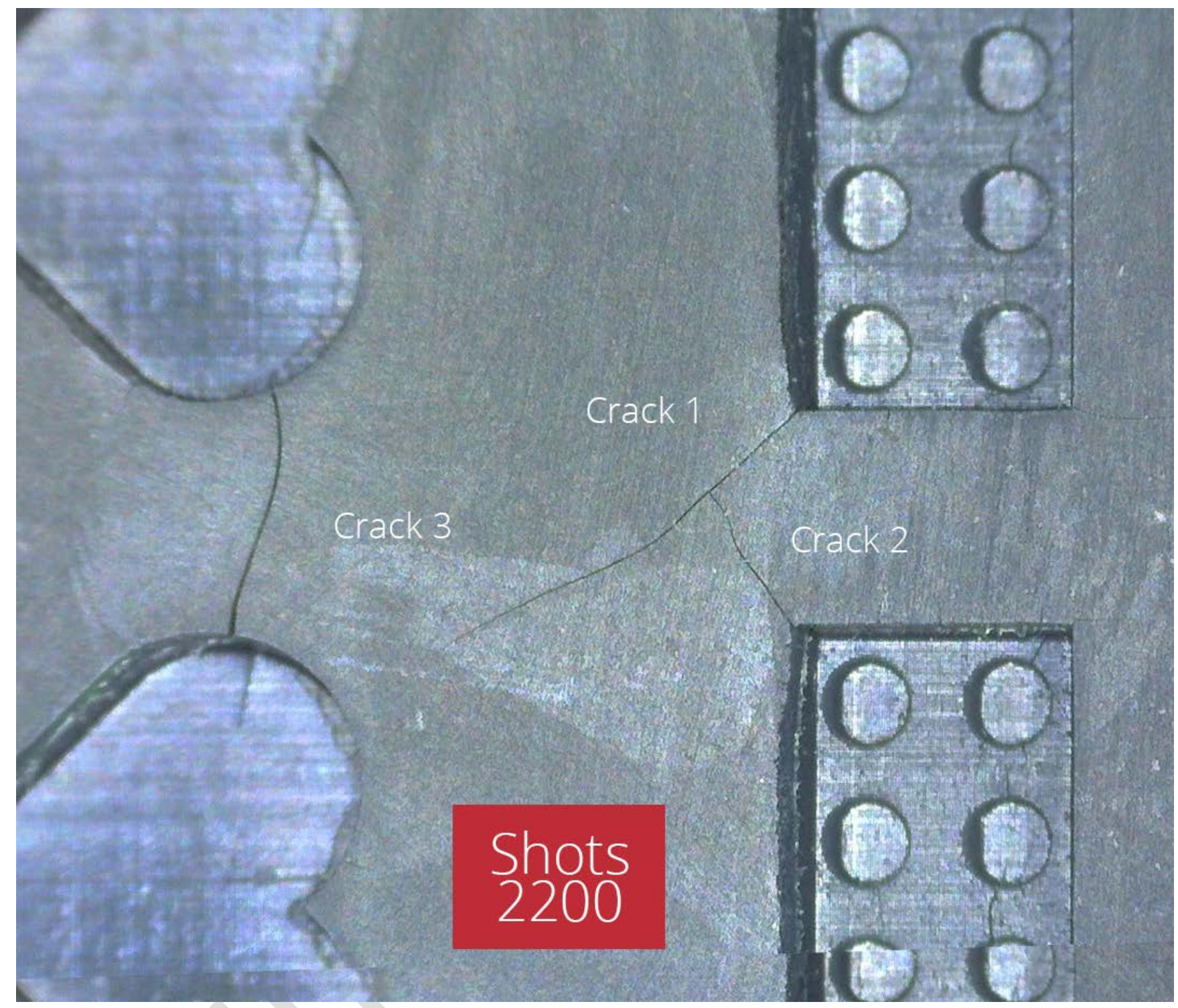

Fig. 5: Cracks of an additively manufactured IM insert with 5\% weight fraction carbon fibers after 2200 shots in [80]. Used with permission. 


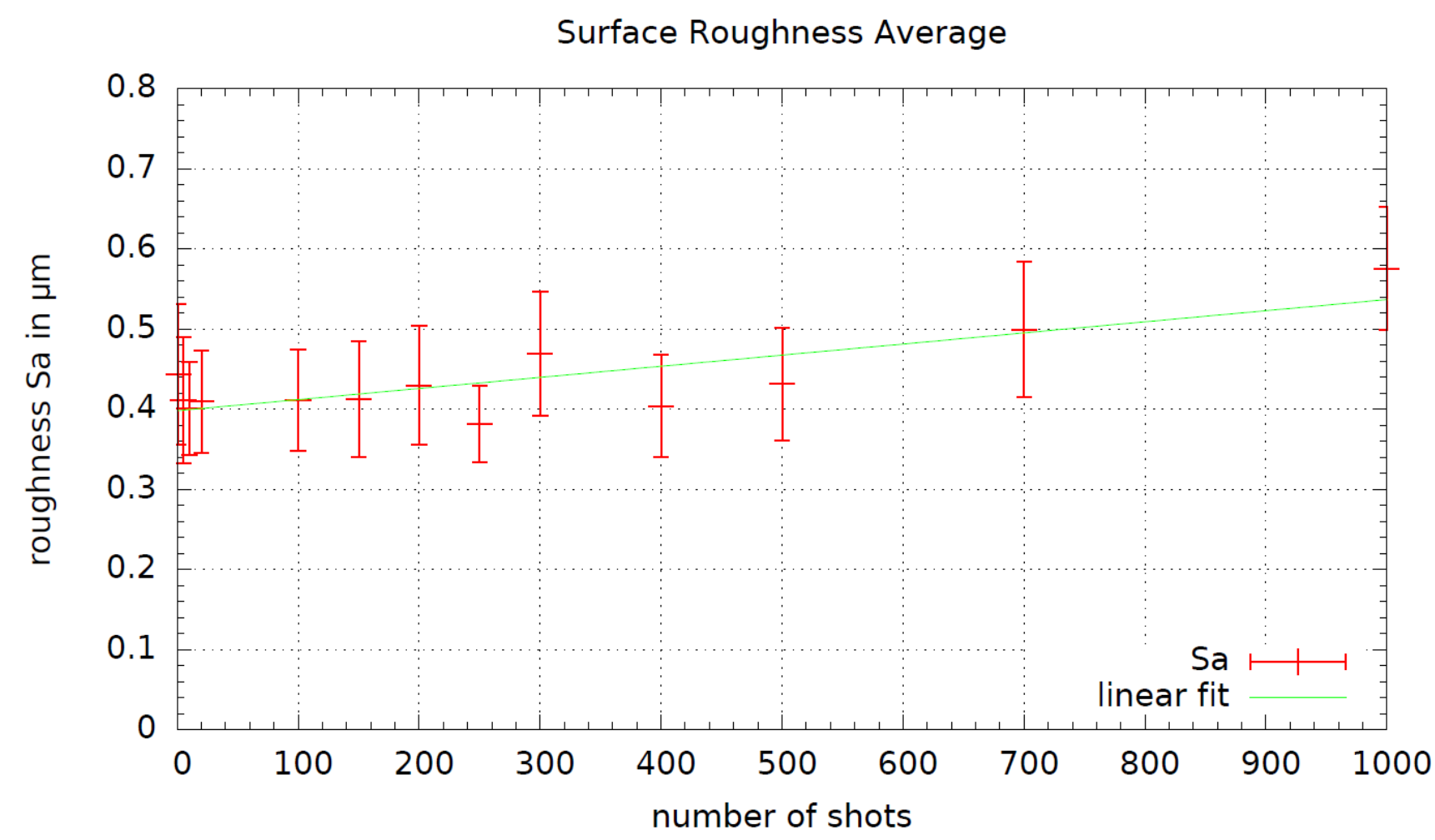

Fig. 6: Surface roughness of an IM insert with $5 \%$ weight fraction of carbon fibers with negligible increase of surface roughness in [80]. Used with permission.

\section{References}

[1] D. Gay, Composite materials: Design and applications. CRC press, 2014.

[2] Q. T. Shubhra, A. Alam, and M. Quaiyyum, "Mechanical properties of polypropylene composites: A review", Journal of thermoplastic composite materials, p. 0892705711428659 , 2011.

[3] M. Sugavaneswaran and G. Arumaikkannu, "Modelling for randomly oriented multi material additive manufacturing component and its fabrication", Materials \& Design, vol. 54, pp. 779-785, 2014.

[4] O. Breuer and U. Sundararaj, "Big returns from small fibers: A review of polymer/carbon nanotube composites", Polymer composites, vol. 25, no. 6, pp. 630-645, 2004.

[5] F. Ning, W. Cong, J. Qiu, J. Wei, and S. Wang, "Additive manufacturing of carbon fiber reinforced thermoplastic composites using fused deposition modeling", Composites Part B: Engineering, vol. 80, pp. 369-378, 2015.

[6] O. Ivanova, C. Williams, and T. Campbell, "Additive manufacturing (am) and nanotechnology: Promises and challenges", Rapid Prototyping Journal, vol. 19, no. 5, pp. 353-364, 2013.

[7] S. Van der Zwaag, A. Grande, W. Post, S. Garcia, and T. Bor, "Review of current strategies to induce self-healing behaviour in fibre reinforced polymer based composites", Materials science and technology, vol. 30, no. 13a, pp. 1633-1641, 2014.

[8] C. Norris, I. Bond, and R. Trask, "The role of embedded bioinspired vasculature on damage formation in self-healing carbon "bre reinforced composites", Composites Part A: Applied 
Science and Manufacturing, vol. 42, no. 6, pp. 639-648, 2011.

[9] A. R. Hamilton, N. R. Sottos, and S. R. White, "Self-healing of internal damage in synthetic vascular materials", Advanced Materials, vol. 22, no. 45, pp. 5159-5163, 2010.

[10] Z. Quan, A. Wu, M. Keefe, X. Qin, J. Yu, J. Suhr, J.-H. Byun, B.-S. Kim, and T.-W. Chou, "Additive manufacturing of multi-directional preforms for composites: Opportunities and challenges", Materials Today, 2015.

[11] L. J. Love, V. Kunc, O. Rios, C. E. Duty, A. M. Elliott, B. K. Post, R. J. Smith, and C. A. Blue, "The importance of carbon fiber to polymer additive manufacturing", Journal of Materials Research, vol. 29, no. 17, pp. 1893-1898, 2014.

[12] M. Shofner, F. Rodriguez-Macias, R. Vaidyanathan, and E. Barrera, "Single wall nanotube and vapor grown carbon fiber reinforced polymers processed by extrusion freeform fabrication

", Composites Part A: Applied Science and Manufacturing, vol. 34, no. 12, pp. 12071217, 2003.

[13] W. Gao, Y. Zhang, D. Ramanujan, K. Ramani, Y. Chen, C. B. Williams, C. C. Wang, Y. C. Shin, S. Zhang, and P. D. Zavattieri, "The status, challenges, and future of additive manufacturing in engineering", Computer-Aided Design, 2015.

[14] A. Le Duigou, M. Castro, R. Bevan, and N. Martin, "3d printing of wood fibre biocomposites: From mechanical to actuation functionality", Materials \& Design, vol. 96, pp. 106-114, 2016.

[15] R. Matsuzaki, M. Ueda, M. Namiki, T.-K. Jeong, H. Asahara, K. Horiguchi, T. Nakamura, A. Todoroki, and Y. Hirano, "Three-dimensional printing of continuous-fiber composites by in-nozzle impregnation", Scientific reports, vol. 6, 2016.

[16] M. C. Serrano, M. C. Gutiérrez, and F. del Monte, "Role of polymers in the design of 3d carbon nanotube-based sca"olds for biomedical applications", Progress in Polymer Science, vol. 39, no. 7, pp. 1448-1471, 2014.

[17] TenCate. (2014). Tencate cetex thermoplastic composites featured on airbus a350 xwb, [Online]. Available: http://www.tencate.com/lmages/141222\%20Press\%20release\% 20TenCate\%20Advanced\%20Composites\%20regarding\%20thermoplastic\%20composites\% 20on\%20Airbus\%20A350\%20XWB\%20for\%20Qatar\%20Airways21- 35239.pdf (visited on $11 / 07 / 2015)$.

[18] M. Biron, Thermoplastics and thermoplastic composites. William Andrew, 2012.

[19] W. Zhong, F. Li, Z. Zhang, L. Song, and Z. Li, "Short fiber reinforced composites for fused deposition modeling", Materials Science and Engineering: A, vol. 301, no. 2, pp. 125-130, 2001.

[20] -, "Research on rapid-prototyping/part manufacturing (rp\&m) for the continuous fiber reinforced composite", Materials and Manufacturing Processes, vol. 16, no. 1, pp. 17-26, 2001.

[21] T. Vaneker and E. Ho"and, "Additive manufacturing with additives: Improving the properties of products produced with mask stereolithography", University of Twente, 2014.

[22] C. Cheah, J. Fuh, A. Nee, and L. Lu, "Mechanical characteristics of fiber-filled photopolymer used in stereolithography", Rapid Prototyping Journal, vol. 5, no. 3, pp. 112-119, 1999.

[23] S. Garoushi, E. Säilynoja, P. K. Vallittu, and L. Lassila, "Physical properties and depth of cure of a new short fiber reinforced composite", Dental Materials, vol. 29, no. 8, pp. 835841, 2013.

[24] T. Monaghan, A. J. Capel, S. Christie, R. Harris, and R. J. Friel, "Solid-state additive manufacturing for metallized optical fiber integration", Composites Part A: Applied Science and Manufacturing, vol. 76, pp. 181-193, 2015. 
[25] A. Gebhardt, M. Knothe, and L. Thurn, "Fiber reinforced 3d-printing", in Proc. of PPS conference, 2014.

[26] M. Shofner, K. Lozano, F. Rodriguez-Macias, and E. Barrera, "Nanofiber-reinforced polymers prepared by fused deposition modeling", Journal of applied polymer science, vol. 89,

no. 11, pp. 3081-3090, 2003.

[27] R. Jacobsen, T. Tritt, J. Guth, A. Ehrlich, and D. Gillespie, "Mechanical properties of vapor-grown carbon fiber", Carbon, vol. 33, no. 9, pp. 1217-1221, 1995.

[28] T. Ozkan, M. Naraghi, and I. Chasiotis, "Mechanical properties of vapor grown carbon nanofibers", Carbon, vol. 48, no. 1, pp. 239-244, 2010.

[29] M. Endo, Y. Kim, T. Hayashi, K. Nishimura, T. Matusita, K. Miyashita, and M. Dresselhaus, "Vapor-grown carbon fibers (vgcfs): Basic properties and their battery applications", Carbon, vol. 39, no. 9, pp. 1287-1297, 2001.

[30] S. Mukai, T. Masuda, K. Hashimoto, and H. Iwanaga, "Physical properties of rapidly grown vapor-grown carbon fibers", Carbon, vol. 38, no. 3, pp. 491-494, 2000.

[31] I. Kong, K. Tshai, and M. E. Hoque, "Manufacturing of natural fibre-reinforced polymer composites by solvent casting method", in Manufacturing of Natural Fibre Reinforced Polymer Composites, Springer, 2015, pp. 331-349.

[32] M. Singh, M. C. Halbig, and S. X. Zhu, "Characterization of matrix materials for additive manufacturing of silicon carbide-based composites", in Advanced Processing and Manufacturing Technologies for Nanostructured and Multifunctional Materials: A Collection of Papers Presented at the 38th International Conference on Advanced Ceramics and Composites January 27-31, 2014 Daytona Beach, Florida, John Wiley \& Sons, Inc., 2015, pp. 4148.

[33] K. Oksman, A. Mathew, D. Bondeson, and I. Kvien, "Manufacturing process of cellulose whiskers/polylactic acid nanocomposites", Composites science and technology, vol. 66, no. 15, pp. 2776-2784, 2006.

[34] O. Carneiro, A. Silva, and R. Gomes, "Fused deposition modeling with polypropylene", Materials \& Design, vol. 83, pp. 768-776, 2015.

[35] P. Dudek, "Fdm 3d printing technology in manufacturing composite elements", Archives of Metallurgy and Materials, vol. 58, no. 4, pp. 1415-1418, 2013.

[36] R. S. Trask, M. Hazzard, and T. Llewellyn-Jones, "Additive layer manufacturing of biologically inspired short "bre reinforced composites", DTIC Document, Tech. Rep., 2014.

[37] J. E. Grady, M. C. Halbig, and M. Singh, "A fully non-metallic gas turbine engine enabled by additive manufacturing", NASA Technical Reports Server, 2015.

[38] J. Glasschroeder, E. Prager, and M. F. Zaeh, "Powder-bed-based 3d-printing of function integrated parts", Rapid Prototyping Journal, vol. 21, no. 2, pp. 207-215, 2015.

[39] L. Petersson, I. Kvien, and K. Oksman, "Structure and thermal properties of poly (lactic acid)/cellulose whiskers nanocomposite materials", Composites Science and Technology, vol. 67, no. 11, pp. 2535-2544, 2007.

[40] D. Bondeson and K. Oksman, "Polylactic acid/cellulose whisker nanocomposites modified by polyvinyl alcohol", Composites Part A: Applied Science and Manufacturing, vol. 38, no. 12, pp. 2486-2492, 2007.

[41] G. Gri"ni, M. Invernizzi, M. Levi, G. Natale, G. Postiglione, and S. Turri, "3d-printable cfr polymer composites with dual-cure sequential ipns", Polymer, 2016.

[42] H. L. Tekinalp, V. Kunc, G. M. Velez-Garcia, C. E. Duty, L. J. Love, A. K. Naskar, C. A. Blue, and S. Ozcan, "Highly oriented carbon fiber-polymer composites via additive manufacturing", Composites Science and Technology, vol. 105, pp. 144-150, 2014.

[43] B. G. Compton and J. A. Lewis, "3d-printing of lightweight cellular composites", Advanced 
Materials, vol. 26, no. 34, pp. 5930"5935, 2014.

[44] Z. Quan, Z. Larimore, A. Wu, J. Yu, X. Qin, M. Mirotznik, J. Suhr, J.-H. Byun, Y. Oh, and T.-W. Chou, "Microstructural design and additive manufacturing and characterization of $3 d$ orthogonal short carbon fiber/acrylonitrile-butadiene-styrene preform and composite", Composites Science and Technology, vol. 126, pp. 139-148, 2016.

[45] N. Li, Y. Li, and S. Liu, "Rapid prototyping of continuous carbon fiber reinforced polylactic acid composites by 3d printing", Journal of Materials Processing Technology, 2016.

[46] A. R. T. Perez, D. A. Roberson, and R. B. Wicker, "Fracture surface analysis of 3d-printed tensile specimens of novel abs-based materials", Journal of Failure Analysis and Prevention, vol. 14, no. 3, pp. 343-353, 2014.

[47] C. E. Duty, T. Drye, and A. Franc, "Material development for tooling applications using big area additive manufacturing (baam)", Oak Ridge National Laboratory (ORNL); Manufacturing Demonstration Facility (MDF), Tech. Rep., 2015.

[48] J. Nixon, B. Dryer, I. Lempert, and D. I. Bigio, "Three parameter analysis of fiber orientation in fused deposition modeling geometries", in Proc. of PPS conference, 2014.

[49] T. Hofstaetter, D. B. Pedersen, J. S. Nielsen, M. Mischkot, and H. N. Hansen, "Investigation of digital light processing using fibre-reinforced polymers", in Proc. of EUSPEN Conference, 2016.

[50] G. R. Bogucki, G. J. S. Hickman, and M. W. Hayes, Extruded deposition of fiber reinforced polymers, US Patent 20,160,082,641, Mar. 2016.

[51] H. Prüÿ and T. Vietor, "Design for fiber-reinforced additive manufacturing", Journal of Mechanical Design, vol. 137, no. 11, p. 111-409, 2015.

[52] K. S. Wagner, "Investigate methods to increase the usefulness of stereolithography $3 d$ printed objects by adding carbon nanotubes to photo-curable resins", University of Minnesota Duluth, 2014.

[53] M. Invernizzi, G. Natale, M. Levi, S. Turri, and G. Griffini, "Uv-assisted 3d printing of glass and carbon fiber-reinforced dual-cure polymer composites", Materials, vol. 9, no. 7, p. 583, 2016.

[54] D. Karalekas and K. Antoniou, "Composite rapid prototyping: Overcoming the drawback of poor mechanical properties", Journal of materials processing technology, vol. 153, pp. 526530, 2004.

[55] G. Zak, M. Sela, V. Yevko, C. Park, and B. Benhabib, "Layered-manufacturing of fiberreinforced composites", Journal of manufacturing science and engineering, vol. 121, no. 3, pp. 448-456, 1999.

[56] S.-H. Chiu, S. T. Wicaksono, K.-T. Chen, C.-Y. Chen, and S.-H. Pong, "Mechanical and thermal properties of photopolymer/cb (carbon black) nanocomposite for rapid prototyping ", Rapid Prototyping Journal, vol. 21, no. 3, pp. 262-269, 2015.

[57] I. Baran, K. Cinar, N. Ersoy, R. Akkerman, and J. H. Hattel, "A review on the mechanical modeling of composite manufacturing processes", Archives of Computational Methods in Engineering, pp. 1-31, 2016.

[58] S. Christ, M. Schnabel, E. Vorndran, J. Groll, and U. Gbureck, "Fiber reinforcement during 3d printing", Materials Letters, vol. 139, pp. 165-168, 2015.

[59] M. Saari, B. Cox, E. Richer, P. S. Krueger, and A. L. Cohen, "Fiber encapsulation additive manufacturing: An enabling technology for 3d printing of electromechanical devices and robotic components", 3D Printing and Additive Manufacturing, vol. 2, no. 1, pp. 32-39, 2015.

[60] M. Saari, B. Cox, M. Galla, P. S. Krueger, E. Richer, and A. L. Cohen, "Multi-material additive manufacturing of robot components with integrated sensor arrays", in Proc. of 
SPIE Vol, vol. 9494, 2015, pp. 949 404-1.

[61] D. Klosterman, R. Charto", N. Osborne, and G. Graves, "Laminated object manufacturing, a new process for the direct manufacture of monolithic ceramics and continuous fiber cmcs", in Proceedings of the 21st Annual Conference on Composites, Advanced Ceramics, Materials, and Structures-B: Ceramic Engineering and Science Proceedings, Volume 18, Issue 4, Wiley Online Library, 1997, pp. 112-120.

[62] MIT Technology Review. (2016). Is 3-d printing the key to cheap carbon-fiber parts?, [Online]. Available: http://www.technologyreview.com/news/546046/is-3-d-printingthe-key-to-cheap-carbon-fiber-parts/ (visited on 01/26/2016).

[63] C. C. Spackman, C. R. Frank, K. C. Picha, and J. Samuel, "3d printing of fiber-reinforced soft composites: Process study and material characterization", Journal of Manufacturing Processes, 2016.

[64] G. J. Ram, Y. Yang, and B. Stucker, "Effect of process parameters on bond formation during ultrasonic consolidation of aluminum alloy 3003", Journal of Manufacturing Systems, vol. 25, no. 3, pp. 221-238, 2006.

[65] G. Janaki Ram, C. Robinson, Y. Yang, and B. Stucker, "Use of ultrasonic consolidation for fabrication of multi-material structures", Rapid Prototyping Journal, vol. 13, no. 4, pp. 226-235, 2007.

[66] Y. Yang, G. J. Ram, and B. Stucker, "An experimental determination of optimum processing parameters for al/sic metal matrix composites made using ultrasonic consolidation", Journal of Engineering Materials and Technology, vol. 129, no. 4, pp. 538-549, 2007. [67] -, "Bond formation and fiber embedment during ultrasonic consolidation", Journal of Materials Processing Technology, vol. 209, no. 10, pp. 4915-4924, 2009.

[68] A. Hehr and M. J. Dapino, "Interfacial shear strength estimates of niti"al matrix composites fabricated via ultrasonic additive manufacturing", Composites Part B: Engineering, vol. 77, pp. 199-208, 2015.

[69] X. Chen, A. Hehr, M. J. Dapino, and P. M. Anderson, "Deformation mechanisms in niti-al composites fabricated by ultrasonic additive manufacturing", Shape Memory and Superelasticity, vol. 1, no. 3, pp. 294-309, 2015.

[70] P. Wolcott, N. Sridharan, S. Babu, A. Miriyev, N. Frage, and M. Dapino, "Characterisation of al-ti dissimilar material joints fabricated using ultrasonic additive manufacturing", Science and Technology of Welding and Joining, 1362171815Y-0 000000 072, 2015. [71] D. Lin, C. R. Liu, and G. J. Cheng, "Single-layer graphene oxide reinforced metal matrix composites by laser sintering: Microstructure and mechanical property enhancement", Acta Materialia, vol. 80, pp. 183-193, 2014.

[72] Graphite additive manufacturing. (2016). Carbon fibre reinforced plastic, [Online]. Available: http://www.graphite.uk.com/services/247-2 (visited on 01/15/2016).

[73] R. Goodridge, M. Shofner, R. Hague, M. McClelland, M. Schlea, R. Johnson, and C. Tuck, "Processing of a polyamide-12/carbon nanofibre composite by laser sintering", Polymer Testing, vol. 30, no. 1, pp. 94-100, 2011.

[74] S. D. Mookhoek, H. R. Fischer, and S. van der Zwaag, "Alginate fibres containing discrete liquid filled vacuoles for controlled delivery of healing agents in fibre reinforced composites", Composites Part A: Applied Science and Manufacturing, vol. 43, no. 12, pp. 2176-2182, 2012.

[75] S. Giannitelli, P. Mozetic, M. Trombetta, and A. Rainer, "Combined additive manufacturing approaches in tissue engineering", Acta biomaterialia, vol. 24, pp. 1-11, 2015.

[76] A. R. Studart, "Additive manufacturing of biologically-inspired materials", Chemical Soci- 
ety Reviews, vol. 45, no. 2, pp. 359-376, 2016.

[77] D.-A. Tuerk, A. Zueger, C. Klahn, M. Meboldt, et al., "Combining additive manufacturing with cfrp composites: Design potentials", in DS 80-4 Proceedings of the 20th International Conference on Engineering Design (ICED 15) Vol 4: Design for X, Design to X, Milan, Italy, 27-30.07. 15, 2015.

[78] M. Mischkot, T. Hofstaetter, N. Bey, D. B. Pedersen, H. N. Hansen, and M. Z. Hauschild, "Life cycle assessment injection mold inserts: Additively manufactured, in brass, and in steel", in Proc. of DTU Sustain Conference, 2015.

[79] T. Hofstaetter, N. Bey, M. Mischkot, A. Lunzer, D. B. Pedersen, and H. N. Hansen, "Comparison of conventional injection mould inserts to additively manufactured inserts using

life cycle assessment", in Proc. of EUSPEN Conference, 2016.

[80] T. Hofstätter, M. Mischkot, D. B. Pedersen, G. Tosello, and H. N. Hansen, "Evolution of surface texture and cracks during injection molding of fiber-reinforced, additively-manufactured, injection molding inserts", in Proceedings of Aspe Summer Topical Meeting 2016, ASPE" The American Society for Precision Engineering, 2016.

[81] A. Cazón, J. G. Prada, E. García, G. S. Larraona, and S. Ausejo, "Pilot study describing the design process of an oil sump for a competition vehicle by combining additive manufacturing and carbon fibre layers", Virtual and Physical Prototyping, vol. 10, no. 3, pp. 149-162, 2015. [82] D. Bourell, B. Stucker, R. Ilardo, and C. B. Williams, "Design and manufacture of a formula sae intake system using fused deposition modeling and fiber-reinforced composite materials", Rapid Prototyping Journal, vol. 16, no. 3, pp. 174-179, 2010.

[83] A. Kantaros and D. Karalekas, "Fiber bragg grating based investigation of residual strains in abs parts fabricated by fused deposition modeling process", Materials \& Design, vol. 50, pp. 44-50, 2013.

[84] X. Tian, T. Liu, C. Yang, Q. Wang, and D. Li, "Interface and performance of 3d printed continuous carbon fiber reinforced pla composites", Composites Part A: Applied Science and Manufacturing, 2016.

[85] S. A. Hinchcli"e, K. M. Hess, and W. V. Srubar, "Experimental and theoretical investigation of prestressed natural fiber-reinforced polylactic acid (pla) composite materials", Composites Part B: Engineering, vol. 95, pp. 346-354, 2016.

[86] J. C. Riddick, M. A. Haile, R. Von Wahlde, D. P. Cole, O. Bamiduro, and T. E. Johnson, "Fractographic analysis of tensile failure of acrylonitrile-butadiene-styrene fabricated by fused deposition modeling", Additive Manufacturing, vol. 11, pp. 49-59, 2016.

[87] T. Hofstätter, I. Gutmann, T. Koch, D.B. Pedersen, G. Tosello, G. Heinz, and H.N. Hansen. "Distribution and Orientation of Carbon Fibers in Polylactic Acid Parts Produced by Fused Deposition Modeling." In Proceedings of Aspe Summer Topical Meeting 2016. ASPE-The American Society for Precision Engineering, 2016.

[88] M.B. Gingerich. Joining Carbon Fiber and Aluminum with Ultrasonic Additive Manufacturing. Diss. The Ohio State University, 2016.

[89] S. Curran, P. Chambon, R. Lind, L. Love, R. Wagner, S. Whitted, David Smith et al. Big Area Additive Manufacturing and Hardware-in-the-Loop for Rapid Vehicle Powertrain Prototyping: A Case Study on the Development of a 3-D-Printed Shelby Cobra. No. 2016-01-0328. SAE Technical Paper, 2016.

[90] Markforged (2016). Markforged Materials, [Online]. Available: https://markforged.com/materials/ (visited on 12/05/2016). 
[91] G. Griffini, M. Invernizzi, M. Levi, G. Natale, G. Postiglione, and S. Turri. "3D-printable CFR polymer composites with dual-cure sequential IPNs." Polymer 91, pp. 174-179, 2016.

[92] X. Tian, T. Liu, Q. Wang, A. Dilmurat, D. Li, and G. Ziegmann. "Recycling and remanufacturing of 3D printed continuous carbon fiber reinforced PLA composites." Journal of Cleaner Production, 2016.

[93] D.A. Türk, R. Kussmaul, M. Zogg, C. Klahn, A.B. Spierings, P. Ermanni, M. Meboldt, Additive manufacturing with composites for integrated aircraft structures, J. Adv. Mater. 3 (2016) 55-69 (ISSN 1070-9789).

[94] K. Picha, C. Spackman, and J. Samuel. "Droplet spreading characteristics observed during 3D printing of aligned fiber-reinforced soft composites." Additive Manufacturing 12, pp. 121-131, 2016.

[95] P. Bettini, G. Alitta, G Sala, and L. Di Landro. "Fused Deposition Technique for Continuous Fiber Reinforced Thermoplastic." Journal of Materials Engineering and Performance: 1-6, 2016.

[96] S. J. Leigh, R. J. Bradley, C. P. Purssell, D. R. Billson, and D. A. Hutchins. "A simple, low-cost conductive composite material for 3D printing of electronic sensors." PloS one 7, no. 11, e49365, 2012. 